\title{
ANALOGIAS EM LIVROS DE QUÍMICA GERAL DESTINADOS AO ENSINO SUPERIOR
}

\author{
Wilmo Ernesto Francisco Junior* \\ Welington Francisco** \\ Ana Carolina Garcia de Oliveira***
}

RESUMO: Apesar da comum utilização das analogias em livros de ciências em geral, estudos envolvendo essa presença em livros de Ensino Superior não são usuais. Nesse sentido, o presente artigo apresenta um estudo sobre as analogias encontradas nos livros de Química Geral voltados ao Ensino Superior, na tentativa de fazer um paralelo com estudos cujas análises se deram para livros de Ensino Médio. Após a leitura integral das obras, identificou-se 212 analogias, as quais foram classificadas conforme sistema de categorias adaptado de outros estudos. Foi observada maior presença de analogias nas obras do Ensino Superior, diferenças no tipo de relação analógica e menor presença de analogias ilustrativas. Também foram discutidos apontamentos sobre um uso mais adequado de algumas das analogias, assim como sobre o papel do professor.

Palavras-chave: Analogia; Livro Didático; Química Geral.

\section{ANALOGIES IN UNDERGRADUATES' GENERAL CHEMISTRY TEXTBOOKS}

ABSTRACT: Although analogies are commonly used in Science textbooks, studies on textbooks used in undergraduate courses are unusual. Taking this into account, this paper presents an analysis on the analogies found in General Chemistry textbooks, aiming to establish a parallel with studies whose focus was on high school textbooks. After reading the textbooks, 212 analogies were identified. They were classified according to a system of categories adapted from studies present at the literature. Undergraduates' textbooks presented more analogies than high school textbooks, differences in analogical relation and a minor presence of illustrative analogies. This work also discusses directions for an adequate use of some analogies, as well as aspects related to the teacher's role.

Keywords: analogies, textbooks, General Chemistry.
* Doutor em Química (tese em Educação Química) pelo Instituto de Química da Universidade Estadual Paulista (UNESP). Professor da Universidade Federal de Alagoas (UFAL), Campus Arapiraca. E-mail: wilmojr@bol.com.br

* * Mestre em Química pelo Instituto de Química da Universidade Estadual Paulista (UNESP). Professor da Universidade Federal do Tocantins, Campus de Gurupi. E-mail: 10welington@bol.com.br

*** Doutoranda em Educação
pela Universidade Estadual
de Campinas (UNICAMP).
Professora do Departamento
de Química da UNIR.
E-mail: acgdeoliveira@yahoo.
com.br




\section{INTRODUCุÃO}

As analogias estão inseridas em diversas situações do dia a dia e, geralmente, configuram-se numa comparação entre dois eventos: um que se pretende explicar, portanto, desconhecido; e o já conhecido, que servirá de referência. A história mostra que as analogias são consoantes à ciência e ao desenvolvimento de inúmeras teorias. O raciocínio analógico está no bojo de renomadas teorias científicas, tais como aquelas apresentadas por Maxwell, Rutherford, Einstein, dentre outros.

No que se refere ao ensino da ciência, trabalhos com interesses em analogias surgem nos anos 60 (OLIVA et al., 2001). Tal interesse se justificou tanto do ponto de vista psicológico como da educação científica. Segundo os mesmos autores, foi no início dos anos 80 que a investigação sobre o tema ganhou propulsão. Apesar do número de pesquisas relacionadas às analogias, grande parte dos professores continua utilizando-as sem se preocupar com um delineamento de metas ou com os possíveis problemas de tal recurso, como apontam diversos trabalhos (TREAGUST et al., 1992; FERRAZ \& TERRAZZAN, 2002; BOZELLI \& NARDI, 2006). O uso de analogias requer cuidado, uma vez que seu emprego de forma simplificada e espontânea pode guiar o pensamento para uma visão concreta e imediata capaz de tolher a abstração necessária à formação do conhecimento científico.

No tocante à definição das analogias, uma variedade de trabalhos também apresenta diferentes propostas (DAGHER, 1995; OLIVA et al., 2001), por vezes similares e até dissonantes em alguns aspectos. Porém, em todas elas prevalece a ideia comum de comparação. No presente contexto, as analogias serão compreendidas como o primeiro passo de um processo cognitivo pelo qual, a partir da identificação das semelhanças entre dois conceitos, é possível fazer inferências sobre o conceito menos conhecido e predizer os aspectos não correspondentes entre ambos. Em outras palavras, a analogia é uma forma de raciocínio a partir do qual se pode conhecer um fenômeno desconhecido mediante o estabelecimento de correspondências com o fenômeno já conhecido. Sob determinado ponto de vista, a analogia é tida como um processo psicológico ou um ato de cognição humana, no entendimento de um conceito por meio de outro. Mas, ao mesmo tempo, sabe-se que as analogias são parte integrante da comunicação humana, isto é, são dispositivos da linguagem que podem funcionar para comunicar algo e são empregadas com o intuito de facilitar tal comunicação.

Portanto, pode-se, ainda, distinguir a analogia enquanto um instrumento para, deliberadamente, facilitar o entendimento de algo a alguém. É óbvio que para esse alguém compreender o objeto de ensino, ele deverá processar a analogia cognitivamente. No entanto, a analogia para aquele que a utiliza como instrumento de ensino/comunicação já foi processada cognitivamente. Essa distinção da analogia entre ato cognitivo e comunicativo raramente é feita. Parece fundamental, todavia, distinguir a analogia como construção cognitiva pessoal e como forma de comunicação, embora na sala de aula isso esteja altamente imbricado.

Enquanto recurso didático, o uso de analogias está relacionado a diversas competências cognitivas, tais como percepção, imaginação, criatividade, memória, 
resolução de problemas, além do desenvolvimento conceitual. Por isso, as analogias foram e são instrumentos extremamente importantes na cognição humana, marcando notadamente a comunicação e a aprendizagem em diversas áreas do conhecimento. Entretanto, analogias funcionam bem quando as semelhanças predominam e tendem a falhar quando as diferenças começam a prevalecer. Nesse sentido, há trabalhos (OLIVA et al., 2001; DUARTE, 2005) cujo enfoque foi mapear as vantagens e desvantagens, as potencialidades e os problemas, bem como o sucesso obtido com a aplicação de analogias, destacando-se as revisões realizadas por Duit (1991) e Dagher (1995).

Duit (1991) aponta que o uso de analogias pode: (i) abrir outras perspectivas de ensino; (ii) facilitar a compreensão e a interpretação de conceitos abstratos por similaridades com conceitos concretos; (iii) motivar os estudantes; (iv) auxiliar o professor a desvelar conceitos prévios dos estudantes sobre áreas já estudadas. Em contrapartida, o mesmo autor considera o uso das analogias como uma "faca de dois gumes", destacando as seguintes desvantagens: (i) atribuição por parte dos alunos de características do domínio que não são compartilhadas pelo conceito-alvo; (ii) transferência de concepções prévias sobre o conceito domínio para o conceito-alvo; (iii) compreensão equivocada do conceito-alvo devido à sobreposição de similaridades superficiais em relação aos aspectos estruturais.

Considerando que as analogias são instrumentos muito presentes em aulas e livros didáticos, este trabalho analisa as analogias presentes nos livros em língua portuguesa de Química Geral para o Ensino Superior, almejando traçar um paralelo com os resultados já divulgados para obras do Ensino Médio brasileiro. Com isso, o intuito é refletir sobre as seguintes questões: As analogias presentes em livros voltados ao Ensino Superior influenciam os autores de livros para o Ensino Médio? As características das analogias em livros de Ensino Médio são similares àquelas em livros de Química Geral? O que pode ser inferido, em termos quantitativos, entre as analogias presentes nos livros de Ensino Médio e do Ensino Superior?

\section{PROCEDIMENTOS METODOLÓGICOS}

O primeiro momento deste trabalho consistiu na seleção das obras para análise, que levou em conta a atualização. Deveriam ser livros que foram publicados ou reeditados em um período não superior a 20 anos, além de constarem como bibliografia básica para Química Geral em diversos cursos superiores do país. Com isso, chegou-se a sete obras que foram lidas na íntegra visando à identificação das analogias presentes. Para facilitar a discussão, os livros receberam códigos de identificação, os quais são apresentados pela Tabela 1.

Foram identificadas como analogias partes contidas no texto que estivessem de acordo com a definição apresentada anteriormente (uma comparação pela qual se pode conhecer um fenômeno desconhecido mediante o estabelecimento de correspondências com o fenômeno já conhecido), ou quando se verificou algum tipo de identificação da analogia. Expressões do tipo "semelhante a...", “isso é como...", 
"fazendo uma analogia...", "analogamente..." foram caracterizadas como indicadoras da presença de analogia. Num segundo momento, as analogias identificadas foram classificadas de acordo com um sistema composto por nove categorias. Tal sistema foi adaptado da proposta apresentada por Thiele e Treagust (1994).

Tabela 1: Livros analisados e os respectivos títulos, autores, editoras, ano de publicação (impressão) do exemplar analisado e edição.

\begin{tabular}{|l|l|l|l|l|l|}
\hline Livro & Título & Autorles) & Editora & Ano & Edição \\
\hline A & Princípios de Química & $\begin{array}{l}\text { Peter Atkins e } \\
\text { Loretta Jones }\end{array}$ & Bookman & 2007 & $3^{\text {a }}$ \\
\hline B & Química Geral & John B. Russel & $\begin{array}{l}\text { Edgard } \\
\text { Blücher }\end{array}$ & 1994 & $2^{\text {a }}$ \\
\hline C & Química Geral & Izrael M. Rozenberg & $\begin{array}{l}\text { Edgard } \\
\text { Blücher }\end{array}$ & 2002 & $1^{\text {a }}$ \\
\hline D & $\begin{array}{l}\text { Química: a matéria e } \\
\text { suas transformações }\end{array}$ & $\begin{array}{l}\text { Joel W. Brady, John W. } \\
\text { Russel, John R. Holum }\end{array}$ & LTC & 2006 & $3^{\text {a }}$ \\
\hline E & $\begin{array}{l}\text { Química: um curso } \\
\text { universitário }\end{array}$ & $\begin{array}{l}\text { Bruce M. Mahan e } \\
\text { Rollie J. Myers }\end{array}$ & $\begin{array}{l}\text { Edgard } \\
\text { Blücher }\end{array}$ & 2007 & $4^{\text {a }}$ \\
\hline F & $\begin{array}{l}\text { Química Geral e } \\
\text { Reações Químicas }\end{array}$ & $\begin{array}{l}\text { John C. Kotze Paul M. } \\
\text { Treichel Jr. }\end{array}$ & Thomson & 2007 & $5^{\text {a }}$ \\
\hline G & $\begin{array}{l}\text { Química: a ciência } \\
\text { central }\end{array}$ & $\begin{array}{l}\text { Theodore L. Brown, } \\
\text { H. Eugene Leway Jr., } \\
\text { Bruce E. Bursten e } \\
\text { Julia R. Burdge }\end{array}$ & $\begin{array}{l}\text { Pearson } \\
\text { Prentice } \\
\text { Hall }\end{array}$ & 2007 & $9^{\text {a }}$ \\
\hline
\end{tabular}

1. Quantidade e frequência das analogias;

2. Conteúdo do conceito-alvo;

3. Tipo de relação analógica entre análogo e alvo;

4. O nível de abstração dos conceitos-alvo e análogos;

5. Formato da apresentação;

6. A posição da analogia em relação ao alvo;

7. O nível de enriquecimento da analogia;

8. O nível de mapeamento feito pelo autor;

9. Apresentação e discussão de limitações.

O primeiro item apresenta a distribuição das analogias em cada obra, ou seja, o total de analogias em cada livro analisado. Na segunda categoria, foram estabelecidos os conceitos-alvo químicos.

O terceiro critério analisou se análogo ${ }^{1}$ e alvo compartilham atributos estruturais, funcionais ou ambos. A relação é estrutural quando o análogo e o alvo compartilham aspectos físicos. Por outro lado, em uma relação funcional, a função 
ou comportamento do análogo é atribuído ao alvo. Uma relação estrutural/funcional combina tanto as relações estruturais como as funcionais. Foi considerada ainda uma quarta divisão (fórmula-funcional), na qual as analogias apresentam aspectos matemáticos em comum.

$\mathrm{Na}$ quarta categoria verificou-se o nível de abstração. As analogias dividem-se basicamente em concretas-concretas, concretas-abstratas e abstratas-abstratas. As analogias concretas-concretas são caracterizadas por ambos os conceitos, análogo e alvo, serem concretos. Por sua vez, as concretas-abstratas possuem o conceito análogo concreto e o conceito-alvo abstrato. Analogias abstratas-abstratas são aquelas nas quais ambos os conceitos comparados são abstratos.

A categoria subsequente diferenciou o formato de apresentação no texto. A analogia foi considerada ilustrativo-verbal quando algum tipo ilustração, além do texto, representava o análogo. Analogias descritas unicamente pelo texto foram consideradas verbais. O sexto critério verificou a posição da analogia em relação ao alvo, isto é, se a analogia foi apresentada antes, após, durante o conceito-alvo ou ainda à margem do texto.

A sétima categoria diz respeito ao nível de enriquecimento, isto é, à extensão das semelhanças apresentadas. As analogias foram classificadas como simples quando um único atributo é compartilhado com o conceito-alvo. Analogias que compartilhassem mais de um atributo com o conceito-alvo foram classificadas como enriquecidas. Quando mais de uma analogia foi empregada para a discussão de um mesmo conceito-alvo, ou quando a analogia sofreu uma modificação para compartilhar um novo atributo, ela foi classificada como estendida. Essa categorização difere da apresentada por Curtis e Reigeluth (1984), também utilizada por Monteiro e Justi (2000). Nesses trabalhos, uma analogia foi classificada como simples quando o conceito análogo era conectado ao alvo por meio de expressões do tipo "é como", “pode ser comparado a”, "é semelhante a”. Já para analogias enriquecidas devia haver explicitação dos atributos compartilhados.

O nível de mapeamento (categoria 8) buscou analisar se o(s) autor(es) discutem os conceitos correspondentes entre o alvo e o análogo e, além disso, até que ponto tal correspondência é debatida. A nona e última categoria verificou a apresentação de limitações da analogia ou alerta sobre a possibilidade da ocorrência de entendimentos não adequados, bem como a discussão de tais limitações. Para isso, houve uma divisão em subcategorias: não reconhece limitações, reconhece limitações e discute as limitações.

\section{RESULTADOS E DISCUSSÃO}

\section{Quantidade de analogias}

A Tabela 2 ilustra a quantidade de analogias para cada obra analisada, cujo total foi de 212, uma média de 30,3 analogias por obra. Pode-se depreender que há uma distribuição de certa forma homogênea quanto à presença das analogias entre 
os livros B, C, E, F e G (24, 15, 16, 21 e 24 respectivamente). Também é possível incorrer que os livros A e D apresentam uma quantidade de analogias superior aos demais. Essas duas obras são responsáveis por 52,8\% (28,3\% livro A e 24,5\% livro D) do total de analogias encontradas, assim como pela elevação da média de analogias por obra. Admitindo que o conteúdo programático presente em cada livro é basicamente o mesmo, tal discrepância parece ser fruto da própria importância que os autores desses livros atribuem a tal recurso didático.

Tabela 2: Quantidade de analogias e frequência média de analogias por capítulo para as obras analisadas.

\begin{tabular}{|c|c|c|c|c|c|c|c|c|c|c|c|c|c|}
\hline \multirow[t]{2}{*}{ Livros } & \multirow[t]{2}{*}{$A$} & \multicolumn{3}{|l|}{ B } & \multirow[t]{2}{*}{ C } & \multicolumn{3}{|l|}{ D } & \multirow[t]{2}{*}{ E } & \multicolumn{3}{|l|}{$F$} & \multirow[t]{2}{*}{ G } \\
\hline & & v. 1 & v. 2 & total & & v. 1 & v. 2 & total & & v.1 & v. 2 & total & \\
\hline $\begin{array}{l}\text { Quantidade } \\
\text { de analogias }\end{array}$ & 60 & 15 & 9 & 24 & 15 & 35 & 17 & 52 & 16 & 14 & 7 & 21 & 24 \\
\hline $\begin{array}{l}\text { Frequência } \\
\text { média de } \\
\text { analogias } \\
\text { por capítulo }\end{array}$ & 3,0 & 1,25 & 0,75 & 1,0 & 0,75 & 2,92 & 1,54 & 2,26 & 0,80 & 1,0 & 0,67 & 0,91 & 0,96 \\
\hline
\end{tabular}

Monteiro e Justi (2000) reportam a presença de 126 analogias, média de 11,5 analogias por coleção didática. Curtis e Reigeluth (1984) e Thiele e Treagust (1994) retratam médias de 13 e 9,3 analogias respectivamente, também para livros de Química. Terrazzan et al. (2005), analisando quatro obras de Biologia, Física e Química, encontraram 414, 71 e 64 incidências, respectivamente. Francisco Junior (2009) relata a presença de 154 analogias nas seis obras de Química aprovadas pelo PNLEM 2007 (Plano Nacional do Livro Didático Para o Ensino Médio), com média de 25,7 analogias por coleção. Todos esses estudos se referem a livros para o Ensino Médio.

Em termos quantitativos, parece haver certa dissonância entre os livros de Química Geral aqui analisados com os livros de Ensino Médio, exceto no caso dos livros aprovados pelo PNLEM 2007. A quantidade e a frequência de analogias são superiores à maioria das obras destinadas ao Ensino Médio, sendo ainda mais discrepantes para os livros A e D. Possivelmente em função dos temas abordados no Ensino Superior, como será visto posteriormente, a importância dada às analogias é maior em obras destinadas a esse nível de ensino.

No entanto, outra questão parece ganhar relevo. Tanto os livros aprovados pelo PNLEM 2007 quanto o livro A possuem qualidade gráfica destacável em comparação aos demais títulos e aos livros analisados em outras pesquisas, cujas edições são menos recentes (THIELE \& TREAGUST, 1994; TERRAZZAN et al., 2005; MONTEIRO \& JUSTI, 2000). O livro D, por sua vez, passou por relativa reformulaç ão em comparação à primeira edição. Esses são indícios de que há uma tendência de maior uso de analogias em livros de melhor qualidade gráfica, em geral (re)editados mais recentemente. Esse pensamento pode estar imbuído pela crença de que as analogias facilitam a aprendizagem por trazer à tona elementos mais próximos da realidade do leitor. 


\section{Conteúdo do conceito-alvo}

No que tange à distribuição das analogias entre os temas químicos, observa-se certa diferença entre os livros destinados ao Ensino Médio e aqueles dedicados ao Ensino Superior (Tabela 3). Enquanto para os livros de Ensino Médio prevalecem analogias para conceitos como estrutura atômica e cinética química, nos livros de Ensino Superior verifica-se, além da estrutura atômica (clássica e moderna), elevada quantidade de analogias para tópicos como composição e propriedades das substâncias (30), geometria e estrutura molecular (29) e ligações químicas (21).

Tabela 3: Distribuição das analogias encontradas por temas.

\begin{tabular}{|c|c|c|c|c|c|c|c|c|c|}
\hline \multirow[t]{2}{*}{ Tópicos } & \multicolumn{7}{|c|}{ Livros } & \multirow[t]{2}{*}{ Total } & \multirow[t]{2}{*}{$\%$} \\
\hline & A & B & C & D & $E$ & $\mathbf{F}$ & G & & \\
\hline $\begin{array}{l}\text { Substâncias: composição } \\
\text { e propriedades }\end{array}$ & 4 & 5 & - & 12 & 3 & 5 & 1 & 30 & 14,2 \\
\hline $\begin{array}{l}\text { Geometria e estrutura } \\
\text { molecular }\end{array}$ & 8 & 2 & 3 & 6 & 1 & 3 & 6 & 29 & 13,7 \\
\hline Estrutura atômica & 4 & 4 & 3 & 7 & - & 4 & 5 & 27 & 12,7 \\
\hline Ligações químicas & 15 & - & 1 & 2 & 1 & - & 2 & 21 & 9,9 \\
\hline $\begin{array}{l}\text { Estrutura atômica } \\
\text { moderna }\end{array}$ & 6 & 3 & - & 5 & - & - & 1 & 1 & 57,1 \\
\hline Cinética & 6 & 1 & - & 2 & - & 2 & 3 & 14 & 6,6 \\
\hline Termoquímica & 5 & - & - & 3 & 1 & 3 & - & 12 & 5,7 \\
\hline Termodinâmica & - & 1 & - & 3 & 2 & - & 3 & 9 & 4,2 \\
\hline Eletroquímica & 2 & 1 & 1 & 1 & 1 & 1 & - & 7 & 3,3 \\
\hline Gases & - & 1 & 1 & 4 & 1 & - & - & 7 & 3,3 \\
\hline Soluções & 1 & 1 & 2 & - & 2 & - & - & 6 & 2,8 \\
\hline $\begin{array}{l}\text { Propriedades } \\
\text { coligativas }\end{array}$ & 1 & - & 4 & - & - & 1 & - & 6 & 2,8 \\
\hline Quantidade de matéria & 1 & 1 & - & 1 & - & 1 & - & 4 & 1,9 \\
\hline Cadeias carbônicas & 2 & 1 & - & 1 & - & - & - & 4 & 1,9 \\
\hline $\begin{array}{l}\text { Elementos e } \\
\text { propriedades periódicas }\end{array}$ & 2 & - & - & - & 2 & - & - & 4 & 1,9 \\
\hline Equilíbrio & 1 & - & - & 2 & 1 & - & - & 4 & 1,9 \\
\hline Bioquímica & 1 & - & - & 1 & & - & 1 & 3 & 1,4 \\
\hline Radioatividade & - & 1 & - & 1 & - & 1 & - & 3 & 1,4 \\
\hline Isomeria & - & 1 & - & - & 1 & - & - & 2 & 0,94 \\
\hline Estequiometria & 1 & - & - & - & - & - & 1 & 2 & 0,94 \\
\hline Polímeros & - & - & - & - & - & - & 1 & 1 & 0,47 \\
\hline Noções de Matemática & - & 1 & - & - & - & - & - & 1 & 0,47 \\
\hline Noções de ciência & - & - & - & 1 & - & - & - & 1 & 0,47 \\
\hline
\end{tabular}


Tal resultado pode ser interpretado pelo fato de esses tópicos surgirem com maior ênfase apenas em cursos superiores. O estudo das geometrias moleculares se intensifica com a Teoria de Repulsão dos Pares Eletrônicos, bem como o estudo das propriedades das substâncias, sobretudo dos sólidos. Isso é corroborado pelos dados, que demonstram a presença de analogias para tais temas em todos os livros analisados. Tal fato não ocorre, por exemplo, com o assunto ligações químicas, que apresenta também elevada quantidade de analogias, mas presente em praticamente uma única obra.

Independente do nível de ensino, tópicos relacionados à estrutura atômica sempre subjazem várias analogias. É interessante notar, também, que algumas analogias parecem inquestionáveis e são empregadas em praticamente todos os livros, sejam de Ensino Médio ou Superior, tais como modelo de Dalton-bola de bilhar, modelo de Thomson-pudim de passas, modelo de Rutherford-sistema planetário e dimensão núcleo/átomo-mosca (formiga)/estádio de futebol (beisebol). Esse uso indiscriminado nem parece decorrer da elevada abstração desse tema, mas de um pensamento historicamente arraigado entre autores de livros didáticos (ou químicos) de que tal assunto deva ser acompanhado de (dessas) analogias, e que elas realmente facilitam a compreensão.

\section{Tipo de relação analógica}

Em termos da relação analógica (Tabela 4), foram encontradas 95 analogias $(44,8 \%)$ do tipo estrutural, $85(40,1 \%)$ funcional e apenas 29 (13,7\%) estrutural-funcional. Monteiro e Justi (2000) reportam a presença de 58\% (73 no total) de analogias funcionais, 38\% (48) de analogias estruturais e 4\% (5) de analogias estruturais-funcionais nos livros pesquisados. Por sua vez, Curtis e Reigeluth (1984) encontraram 88\% de relações analógicas funcionais, 10\% estruturais e 2\% estruturais-funcionais. Francisco Junior (2009) assinala que 49,4\% das analogias encontradas foram do tipo funcional, 35,7\% estrutural e 11,7\% estrutural-funcional.

Tabela 4: Quantidade de analogias segundo o tipo de relação analógica.

\begin{tabular}{|l|l|l|l|}
\hline \multirow{2}{*}{} & \multicolumn{3}{|l|}{ Tipo de relação analógica } \\
\cline { 2 - 4 } & estrutural & funcional & estrutural-funcional \\
\hline Livro A & 31 & 21 & 8 \\
\hline Livro B & 11 & 12 & 0 \\
\hline Livro C & 6 & 6 & 3 \\
\hline Livro D & 18 & 24 & 8 \\
\hline Livro E & 9 & 5 & 2 \\
\hline Livro F & 6 & 10 & 5 \\
\hline Livro G & 14 & 7 & 3 \\
\hline total & $\mathbf{9 5}$ & $\mathbf{8 5}$ & $\mathbf{2 9}$ \\
\hline
\end{tabular}


Todas as pesquisas que tiveram livros de Ensino Médio como objeto incorrem para maior quantidade de analogias do tipo funcional. Já para os livros aqui analisados, verificou-se maior parcela de analogias estruturais. A principal razão para isso pode ser a natureza dos conceitos químicos para os quais são empregadas analogias. Um dos tópicos muito abordado em livros de Química Geral é o estudo da composição, estrutura e propriedades de sólidos. Boa parte das analogias decorre desse tópico, sendo praticamente todas elas de caráter estrutural. Outro tópico também recorrente no Ensino Superior, e geralmente ausente no Ensino Médio, é a teoria atômica moderna, responsável também por analogias do tipo estrutural.

Além de analogias funcionais, estruturais e estruturais-funcionais, foram encontradas, ainda, três analogias $(1,4 \%)$ do tipo fórmula-funcional. Analogias desse tipo configuram-se por também apresentarem aspectos matemáticos em comum, como o exemplo a seguir:

Se o significado da equação anterior [ $[v=v]$ não está claro, imagine a analogia: um trem de carga de carros passa por um cruzamento. Você poderia calcular a velocidade do trem pelo produto da frequência dos carros que passa (o número que passam por segundo vezes o comprimento de cada carro). A frequência vezes o comprimento é igual à velocidade. (LIVRO B, p. 226)

Nesse caso, para aumentar a similaridade e possibilitar maior esclarecimento dos aspectos matemáticos em comum, os autores poderiam ter acrescentado a equação para o cálculo da velocidade do trem.

Considerando as coleções separadamente, os livros A, E e G encerram mais analogias do tipo estrutural do que funcional ou estrutural-funcional, sendo que os livros A e $\mathrm{G}$ apresentam um número bem mais elevado de analogias estruturais, comparado às demais categorias de relação analógica. Esse fator é o que prevalece na maior ocorrência de analogias estruturais. Nas outras obras, não se verifica tanta dissonância em termos numéricos com relação às analogias estruturais e funcionais.

Quando análogo e alvo compartilham tanto atributos funcionais quanto atributos estruturais, fato incomum nos resultados apresentados, é provável que as correspondências prevaleçam em relação às limitações. Entretanto, não são todas as analogias que permitem isso, e analogias somente do tipo estrutural ou somente do tipo funcional podem atingir os objetivos delineados, assim como analogias do tipo estrutural-funcional podem trazer sérios prejuízos à aprendizagem. O livro E, por exemplo, apresenta uma analogia entre o equilíbrio do sistema $\mathrm{CaCO}_{3}(\mathrm{~s}) \Leftrightarrow \mathrm{CaO}(\mathrm{s})+\mathrm{CO}_{2}(\mathrm{~g})$ e o equilíbrio de um líquido com seu vapor. Os autores afirmam que "esse sistema químico é rigorosamente análogo ao sistema físico que consiste de uma fase condensada e seu vapor” (LIVRO E, p. 83).

Tal analogia compartilha tanto atributos estruturais (modelo particulado da matéria útil em ambos os casos; sistema inicial com menor volume e menor espaço entre as partículas; o sistema final apresenta partículas mais espaçadas entre si e maior volume) quanto funcionais (aumento de entropia do sistema, mudança de estado físico entre o sistema inicial e final). Ainda que diferenciar transformações 
químicas de transformações físicas seja complexo e às vezes pouco esclarecedor, como um sistema químico pode ser "rigorosamente análogo" a um sistema físico? Em um sistema físico não há alterações em nível atômico-molecular. Logo, mesmo se tratando de uma analogia que compartilha características estruturais e funcionais, a aprendizagem pode ser prejudicada, uma vez que é possível a transposição de ideias inválidas de um conceito ao outro.

\section{Nível de abstração}

Um dos principais aspectos a serem considerados na seleção e no uso de uma analogia é a familiarização dos alunos; em outras palavras, os alunos devem compreender o análogo para compreender o conceito-alvo. $\mathrm{Na}$ medida em que uma analogia demasiadamente abstrata torna-se pouco familiar aos estudantes, esta pode não contribuir para a transposição das ideias similares de um fenômeno ao outro. Sempre que possível, é recomendável uma analogia pessoalmente significativa, o que a torna potencialmente mais familiar aos estudantes.

Os resultados apresentados pela Tabela 5 mostram que isso parece ter sido levado em conta nas analogias propostas nos livros analisados. Verificou-se que a grande maioria $(156-73,6 \%)$ das analogias encontradas na obras analisadas é do tipo concreta-abstrata. Analisando-se as coleções separadamente, evidencia-se também o predomínio de analogias do tipo concreta-abstrata sobre as demais. Analogias abstratas-abstratas e concretas-concretas correspondem respectivamente a $7,5 \%$ e $18,9 \%$ do total das analogias encontradas.

Tabela 5: Quantidade de analogias segundo o nível de abstração e o formato de apresentação.

\begin{tabular}{|l|l|l|l|l|l|}
\hline & \multicolumn{2}{|l|}{ Nivel de abstração } & \multicolumn{2}{l|}{ Forma de apresentação } \\
\cline { 2 - 6 } & $\begin{array}{l}\text { concreta- } \\
\text { abstrata }\end{array}$ & $\begin{array}{l}\text { concreta- } \\
\text { abstrata }\end{array}$ & $\begin{array}{l}\text { concreta- } \\
\text { abstrata }\end{array}$ & verbal & $\begin{array}{l}\text { ilustrativa- } \\
\text { verbal }\end{array}$ \\
\hline Livro A & 44 & 7 & 9 & 52 & 8 \\
\hline Livro B & 23 & 1 & 0 & 17 & 7 \\
\hline Livro C & 7 & 0 & 8 & 15 & 0 \\
\hline Livro D & 47 & 0 & 5 & 42 & 10 \\
\hline Livro E & 11 & 4 & 1 & 13 & 3 \\
\hline Livro F & 13 & 3 & 5 & 17 & 4 \\
\hline Livro G & 11 & 1 & 12 & 17 & 7 \\
\hline total & $\mathbf{1 5 6}$ & $\mathbf{1 6}$ & $\mathbf{4 0}$ & $\mathbf{1 7 3}$ & $\mathbf{3 9}$ \\
\hline
\end{tabular}

Monteiro e Justi (2000) e Francisco Junior (2009) também relatam maior ocorrência de analogias concreta-abstrata em relação às categorias concreta-concreta e abstrata-abstrata. Todavia, vale sublinhar que apenas o fato de o conceito 
análogo ser concreto não torna a analogia adequada. O livro A, por exemplo, apresenta uma analogia na qual soluções com capacidade tamponante são relacionadas a ralos: "Um tampão é uma mistura de um par conjugado ácido fraco-base fraca que estabiliza o pH de uma solução, fornecendo uma fonte de prótons e um ralo de prótons" (LIVRO A, p. 504). Tal analogia compara questões muito diferentes, regidas por fundamentos distintos e que não fazem sentido em ser comparadas.

\section{Forma de apresentação}

Representações visuais são importantes na compreensão da analogia, pois fundamentam a formação dos modelos mentais a partir da percepção e da imaginação. Portanto, apresentar, quando possível, imagens pelas quais o conceito em estudo possa ser representado, discutido e debatido, é uma forma de garantir maior compreensão dos estudantes. O objetivo de se empregar as ilustrações é possibilitar ao estudante a formulação de ideias abstratas. Esse pode ser um dos fatores que levam os autores a optar por analogias ilustrativo-verbais. Isso não implica, todavia, que a simples visualização de uma estrutura leve à formulação de um conceito. Ao contrário, todo conceito, ao ser formulado, tanto na história da ciência como na estrutura cognitiva do aluno, passa por uma série de modificações e aperfeiçoamentos. Além disso, é importante ter cuidado quanto às impressões imediatas que impedem o raciocínio abstrato e fomentam a formulação de obstáculos à aprendizagem.

Das 145 analogias identificadas, nenhuma é apenas ilustrativa. Grande parte $(173-81,6 \%)$ apresenta-se sob a forma verbal e apenas 18,4\% (39) sob a forma ilustrativa-verbal. Um exemplo de certa forma interessante desse último caso é a analogia estabelecida entre a energia de ativação e uma rede de voleibol (Figura 1).

Figura 1: Analogia ilustrativa-verbal empregada pelo livro F (p. 26).

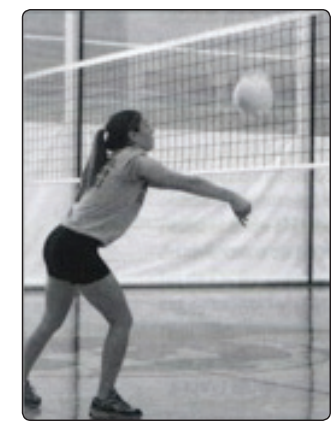

Uma analogia à energia de ativação química.

Para que a bola de voleibol passe por cima da rede, a atleta deve fornecer a ela energia suficiente.

Para que a bola supere a rede, é necessário que a atleta imprima uma energia suficiente durante o contato com a bola, assim como para que a reação ocorra, a colisão entre as partículas deve atingir a energia de ativação. A ilustração facilita 
o dimensionamento da questão energética, até mesmo no aspecto gráfico, embora valha ressaltar limitações dessa analogia, como a não existência de reagentes e produtos, a não modificação de rearranjos moleculares, entre outras.

Comparando as obras, em todas elas prevalecem analogias descritas verbalmente, diferentemente do equilibrio entre analogias verbais e ilustrativa-verbais assinalado por Francisco Junior (2009). Esse equilíbrio também é reportado por Monteiro e Justi (2000) e Thiele e Treagust (1994). Já Curtis e Reigeluth (1984) assinalam, para 29\% de analogias ilustrativa-verbais e $71 \%$ de analogias verbais, resultados mais próximos dos aqui obtidos, que podem estar calcados na hipótese de que estudantes de Ensino Superior possuem mais habilidade em imaginar algo abstrato do que estudantes de Ensino Médio. Dessa forma, os autores de livros para o nível médio preocupam-se, em maior grau, com a presença de ilustrações no sentido de facilitar a imaginação do leitor. Outra hipótese, de certa forma corroborada pela anterior, é a qualidade gráfica superior dos livros de Ensino Médio. Isso possibilita a presença de ilustrações em maior quantidade e qualidade.

\section{Posição das analogias}

Monteiro e Justi (2000) concordam com Curtis e Reigeluth (1984) quanto ao fato de que as analogias posicionadas antes ou durante a apresentação do alvo podem ser mais eficazes. Nesses casos, elas permitem estabelecer comparações mais diretas, pois ao ser apresentado ao conceito-alvo, o aluno pode, simultaneamente, estabelecer as relações necessárias (MONTEIRO \& JUSTI, 2000). Observando-se a Tabela 6 , nota-se que no caso dos livros aqui analisados, há um claro predomínio de analogias apresentadas concomitantemente ao conceito-alvo ( 94 - 44,3\%), sobretudo no livro E, em que só existem nessa situação. As analogias anteriores ao alvo também aparecem em quantidade significativa, representando 19,3\% dos casos. Já aquelas à margem detêm o menor índice (12,3\%). Nessa posição, as analogias podem adquirir apenas um caráter de reforço, sendo desvalorizadas, pois nenhuma menção é feita no corpo texto.

Tabela 6: Analogias de acordo com a posição em relação ao alvo e o nível de enriquecimento.

\begin{tabular}{|l|l|l|l|l|l|l|l|}
\hline & \multicolumn{3}{|l|}{ Posição } & \multicolumn{2}{l|}{ Nivel de enriquecimento } \\
\cline { 2 - 9 } & antes & durante & após & à margem & simples & enriquecida & estendida \\
\hline Livro A & 19 & 18 & 17 & 6 & 47 & 0 & 13 \\
\hline Livro B & 1 & 11 & 6 & 6 & 18 & 6 & 0 \\
\hline Livro C & 6 & 7 & 2 & 0 & 13 & 2 & 0 \\
\hline Livro D & 6 & 25 & 13 & 8 & 39 & 10 & 3 \\
\hline Livro E & 0 & 16 & 0 & 0 & 12 & 4 & 0 \\
\hline Livro F & 4 & 6 & 7 & 4 & 14 & 4 & 3 \\
\hline Livro G & 5 & 11 & 6 & 2 & 14 & 4 & 6 \\
\hline total & $\mathbf{4 1}$ & $\mathbf{9 4}$ & $\mathbf{5 1}$ & $\mathbf{2 6}$ & $\mathbf{1 5 7}$ & $\mathbf{3 0}$ & $\mathbf{2 5}$ \\
\hline
\end{tabular}


Analogias feitas após o conceito-alvo também podem ser interessantes. Segundo Francisco Junior (2009):

(...) há de se considerar que uma analogia pode ser empregada como forma de avaliação do conhecimento dos alunos. Após discutir um dado tema, o professor/autor pode apresentar uma analogia para que os estudantes façam as correspondências entre análogo e alvo. Quanto mais atributos similares e não similares os estudantes conseguirem identificar por si, maior foi a compreensão sobre aquele determinado assunto. Essa é uma função das analogias que não pode ser ignorada, mas que poucos autores de livros e poucos pesquisadores consideram. (FRANCISCO JUNIOR, 2009, p. 135)

A posição das analogias depende dos objetivos de quem a propõe, assim como da natureza dos conceitos-alvo e análogos. Assim, antes e durante podem ser efetivas na compreensão do conceito, permitindo a construção conjunta do conhecimento. Por sua vez, podem auxiliar na avaliação da compreensão quando aparecem após o alvo. Entretanto, à margem sua própria importância é diminuída, daí a baixa ocorrência nessa posição.

\section{Nível de enriquecimento}

Como pode ser visto na Tabela 6, a maioria das analogias (157 $74,0 \%$ ) foi classificada como simples. Analogias do tipo enriquecidas e estendidas correspondem a $30(14,2 \%)$ e $25(11,8 \%)$ incidências, respectivamente. Esses números são razoavelmente diferentes dos apresentados por Francisco Junior (2009) e indicam que os livros de Química Geral tendem a apresentar mais analogias simples. Isso pode ser explicado, em parte, pelos próprios conceitos para os quais são empregadas as analogias. Como visto anteriormente, os livros de Química Geral, diferentemente daqueles destinados ao Ensino Médio, possuem mais analogias do tipo estrutural. Há uma tendência de que analogias estruturais sejam simples, pois geralmente se compara um único atributo, como por exemplo estrutura do fulereno-bola de futebol, estrutura do DNA-espiral de caderno, átomo de Dalton-bola de sinuca, dentre outras verificadas durante a análise.

Analogias simples são mais propensas a ocasionar problemas de aprendizagem, visto que os estudantes podem encontrar dificuldades para identificá-las e, consequentemente, não a aceitarem. Isso ocorre devido à baixa similaridade e, por conseguinte, às várias limitações que as analogias simples apresentam. Quando mais de um atributo de um análogo é empregado na discussão de mais de um conceito-alvo, ou mais de um análogo é utilizado para ensinar um mesmo conceito-alvo, a analogia pode ser classificada com ampliada ou estendida, atingindo assim, o mais alto nível de enriquecimento. Contudo, um alto nível de enriquecimento também não significa, necessariamente, uma analogia mais adequada. Em alguns casos, devido ao uso de muitos análogos na tentativa de explicar um único conceito-alvo, as comparações podem ser confusas para os estudantes, o que os levaria a não estabelecer as correspondências adequadamente. 


\section{Mapeamento das similaridades}

A não discussão da analogia impele ao professor e/ou estudante a responsabilidade em estabelecer não só as similaridades, mas também as limitações da analogia. Isso pode resultar, além da não identificação pelo leitor das similaridades estabelecidas pelo autor (o que torna a analogia inútil sob o ponto de vista de facilitar a aprendizagem), na transposição de comparações inválidas que, por sua vez, podem criar obstáculos de aprendizagem. Por isso, seria de grande valia o uso de analogias acompanhadas da identificação dos atributos compartilhados entre os conceitos-alvo e análogos. Indubitavelmente, os livros didáticos não dão conta de tudo que possa ser relevante para a aprendizagem, o que realça a importância dos professores na reflexão desses variantes.

Tabela 7: Classificação das analogias conforme a presença do mapeamento das similaridades e das limitações.

\begin{tabular}{|l|l|l|l|l|l|}
\hline & \multicolumn{2}{l|}{$\begin{array}{l}\text { Mapeamento das } \\
\text { similaridades }\end{array}$} & \multicolumn{2}{l|}{ Limitações } \\
\cline { 2 - 6 } & sim & não & reconhece & $\begin{array}{l}\text { não } \\
\text { reconhece }\end{array}$ & discute \\
\hline Livro A & 14 & 46 & 0 & 60 & 0 \\
\hline Livro B & 17 & 7 & 4 & 20 & 4 \\
\hline Livro C & 9 & 6 & 0 & 15 & 0 \\
\hline Livro D & 10 & 42 & 3 & 49 & 1 \\
\hline Livro E & 12 & 4 & 1 & 15 & 1 \\
\hline Livro F & 11 & 10 & 1 & 20 & 1 \\
\hline Livro G & 13 & 11 & 1 & 23 & 1 \\
\hline total & $\mathbf{6 7}$ & $\mathbf{7 8}$ & $\mathbf{1 0}$ & $\mathbf{2 0 2}$ & $\mathbf{8}$ \\
\hline
\end{tabular}

Sob esse ponto de vista, os livros analisados apresentam certo equilíbrio, pois em 67 casos (46,2\% das analogias) há o mapeamento das similaridades entre alvo e análogo, e em 78 (53,8\%) casos não há. Porém, como pode ser visto na Tabela 7, dos 78 casos nos quais não são estabelecidas as correspondências entre os conceitos-alvo e análogos, 46 deles estão presentes no livro A, o que corresponde a 76,7\% das analogias encontradas nessa obra.

\section{Apresentação e discussão das limitações}

Preocupante é a situação dos limites de uma analogia. Predomina em todos os livros, independente do nível de ensino, a quase ausência de discussões que abarquem as limitações das analogias (MONTEIRO \& JUSTI, 2000; FRANCISCO JUNIOR, 2009). Na grande maioria não há reconhecimento dos limites e dos cuidados a serem tomados. Esse baixo índice de reconhecimento e de discussão 
das limitações pode, de acordo com Monteiro e Justi (2000), ser ancorado por três suposições: (i) os autores pensam que as limitações analógicas não são relevantes para serem incluídas nos livros; (ii) os autores presumem que os alunos não têm dificuldades em estabelecer as relações analógicas corretas; e (iii) os autores delegam aos professores a responsabilidade de estabelecer os limites das analogias. Em todos os casos faz-se necessário o papel do professor em discutir as limitações e, como já apresentado, em alguns casos, as correspondências das analogias presentes nos livros.

Novamente, vale refletir que o livro didático sempre possuirá suas limitações, por razões como espaço e até mesmo concepções pedagógicas de ensino que o norteiam. Ainda que o livro seja bom, este nunca abarcará tudo aquilo que pode ser importante.

\section{CONSIDERACְÕES FINAIS}

No cerne das reflexões sobre o uso das analogias como instrumento didático, assim como de outros, está o planejamento e o reconhecimento de suas vantagens e desvantagens. Nesse sentido, o professor é um ator essencial que tem sua responsabilidade aumentada, pois na grande parte das analogias presentes em livros didáticos, seja qual for o nível de ensino, torna-se sua a incumbência discutir os atributos correspondentes e não correspondentes, bem como as limitações das analogias. É importante, por parte do professor, a ciência dessa responsabilidade devido aos próprios aspectos limitadores do livro didático, além das diferenças culturais resultantes de sua produção. Considerando ainda que a maior parte das obras aqui investigadas foi traduzida, não se referindo, portanto, aos aspectos culturais brasileiros que ainda variam de região para região e de universidade para universidade, muitas reflexões, não somente em relação às analogias, são pertinentes no momento do emprego dessas obras pelos docentes em suas respectivas disciplinas.

Sobre os resultados em si, não se observou influência direta, ao menos no que se refere à repetição de analogias, entre os livros de Química Geral analisados e os livros de Ensino Médio avaliados por Monteiro e Justi (2000) e Francisco Junior (2009), exceto no caso dos modelos atômicos. Parecem ser inquestionáveis as clássicas analogias da bola de bilhar, do pudim de passas e do sistema solar, independente do nível de ensino. Sobre isso, Francisco Junior (2009) traz o seguinte apontamento:

Com o advento da tecnologia, o uso de muitas analogias, sobretudo algumas de caráter estrutural, não faz mais sentido. Como exemplo pode ser dado a analogia átomo de Rutherford-sistema solar, a qual é empregada para facilitar a imaginação, em termos da localização espacial, entre núcleo e elétrons, tendo sido utilizada pelo próprio Rutherford. Porém, atualmente, a representação imagética desse modelo atômico pode propiciar muito bem a ideia de que os elétrons giram ao redor do núcleo, sem se recorrer ao aposto, "como os planetas ao redor do sol”. Até porque, para que tal analogia seja empregada adequadamente, haveria a necessidade de se discutir, por exemplo, as diferenças nos tipos de forças que regem o movimento de planetas e elétrons em torno do sol e do núcleo atômico respectivamente. (FRANCISCO JUNIOR, p. 140-141). 
Ainda comparando os livros de Ensino Médio e Superior, é percebida certa superioridade destes últimos em termos quantitativos, além de diferenças em termos do tipo de relação analógica, do nível de enriquecimento e da menor presença de analogias ilustrativas. Tais resultados podem ocorrer em função dos assuntos abordados em um e outro nível de ensino. Em nível superior, temas como composição e propriedades da matéria e geometria e estrutura molecular ganham maior profundidade. São justamente esses os temas em que se verificou o maior número de analogias.

Todavia, no que concerne aos aspectos mais preocupantes do uso desse recurso, os mesmos prevalecem nos livros de Química Geral avaliados. Da forma como são empregadas as analogias, muitas delas poderiam ser suprimidas pelos autores com pouca perda de compreensão do conceito em questão.

Um último aspecto interessante que vale ser destacado é a tendência dos livros de melhor qualidade gráfica fazerem uso de analogias em maior grau. No caso das obras aprovadas pelo PNLEM 2007, todas coloridas, a frequência de analogias é bem superior em comparação aos livros de Química mais antigos (FRANCISCO JUNIOR, 2009). No tocante aos livros de Química Geral destinados ao Ensino Superior, o livro A, que apresenta a maior quantidade e a maior média de analogias por capítulo (3 analogias/capítulo), é o único colorido integralmente. Por sua vez, o livro D, colorido em boa parte, aparece como a segunda obra com mais analogias e com a maior média de analogias por capítulo. Coincidência ou não, esses são aspectos que merecem atenção em trabalhos futuros.

\section{NOTA}

${ }^{1}$ Diversos autores utilizam diferentes denominações para os conceitos comparados em uma analogia; porém, a discordância semântica desses termos não indica que eles sejam percebidos diferentemente. Neste trabalho, será adotada a denominação de conceito-alvo para aquele conceito que se quer aprender (ensinar), e de conceito análogo para aquele que servirá de subsídio para o alcance do primeiro.

\section{REFERÊNCIAS}

BOZELLI, F. K.; NARDI, R. O uso de analogias no ensino de física em nível universitário: interpretações sobre os discursos do professor e dos alunos. Revista Brasileira de Pesquisa em Educação em Ciências, São Paulo, v. 6, n. 3, p. 77-100, 2006.

CURTIS, R. V.; REIGELUTH, C. M. The use of analogies in written text. Instructional Science,[s.1], v. 13, n. 2, p. 99-117, 1984.

DAGHER, Z. R. Review of studies on the effectiveness of instructional analogies in science education. Science Education, [s.l], v. 79, n. 3, p. 295-312, 1995.

DUARTE, M. C. Analogias na educação em ciências: contributos e desafios. Investigações em Ensino de Ciências, Porto Alegre, v. 10, n. 1, p. 7-29, 2005.

DUIT, R. On the role of analogies and metaphors in learning science. Science Education, [s.l], v. 75, n. 6, p. 649-672, 1991. 
FERRAZ, D. F.; TERRAZZAN, E. A. O uso espontâneo de analogias por professores de biologia: observações da prática pedagógica. Ensaio - Pesquisa em Educação em Ciências, Belo Horizonte, v. 4, n. 1, p. 107-118, 2002.

FRANCISCO JUNIOR, W. E. Analogias em livros didáticos de química: o caso das obras aprovadas pelo PNLEM 2007. Ciências \& Cognição, Rio de Janeiro, v. 14, n. 1, p. 121-143, 2009.

MONTEIRO, I. V.; JUSTI, R. Analogias em livros didáticos de química destinados ao ensino médio. Investigações em Ensino de Ciências, Porto Alegre, v. 5, n. 2, p. 67-91, 2000.

OLIVA, J. M. et al. Una propuesta didáctica basada en la investigación para el uso de analogías en la enseñanza de las ciencias. Enseñanza de las Ciencias, Vigo, Espanha, v. 19, n. 3, p. 453-470, 2001.

TERRAZZAN, E. A. et. Al. Estudo das analogias utilizadas em coleções didáticas de física, química e biologia. Enseñanza de las Ciencias, Vigo, Espanha, número extra, 2005.

THIELE, R.; TREAGUST, D. An interpretative examination of high school chemistry teachers' analogical explanations. Journal of Research in Science Teaching, [s.l], v. 31, n. 3, p. 227-242, 1994.

TREAGUST, D. F.; DUIT, R.; JOSLIN, P.; LINDAUER, I. Science teachers' use of analogies: observations from classroom practice. International Journal of Science Education, [s.l], v. 14, n. 4, p. 413-422, 1992. 
